\title{
Obituary Makoto Kikuchi
}

\author{
Niki Netzer
}

Received: 24 April 2014 / Accepted: 28 April 2014 / Published online: 17 May 2014

(C) Springer-Verlag Berlin Heidelberg 2014

Our beloved friend and colleague Makoto Kikuchi has died after a short battle with cancer on March 27, 2014. He was in close contact with me over the last months as he managed the handover of his chairmanship of the Japanese Academy of Dental Sleep Medicine and his editorial board position with this journal to his colleague and scholar Morio Tonogi. Makoto and I discussed an operation of his tumor, but Makoto had decided after talks with his close ones and local physicians to disregard further invasive therapies-a personal decision we have to accept with full respect. Makoto had such a fulfilled life that he could "close out", to use that term from baseball, Japans most popular sport, without remorse.

Beloved husband, father, and grandfather in his hometown Narita, successful dentist, oral surgeon, and teacher at Japan's most respected dental medical school, the Tokyo Dental College, we can without disrespect to others name him as the father of dental sleep medicine in Asia. He started with mandibular advancement therapies more than 25 years ago and was in close contact with other founders of dental therapies for sleep disordered breathing in the Americas, Europe, and Australia. Within sleep disordered breathing, he was specialized in facial patterns of children connected to the development of SDB. He published several often cited original articles and a book with Wiley Publisher on this topic.

In "Sleep and Breathing", Makoto played an important role as he was the founder of the Japanese Academy of Dental Sleep Medicine and affiliated it with our journal "Sleep and

N. Netzer $(\bowtie)$

Hermann Buhl Institute for Hypoxia and Sleep Medicine Research, Bad Aibling, Germany

e-mail: nikinetzer@yahoo.com
Breathing". Therefore, the Japanese society was alongside the AADSM as the second society on which the subscriber basis of the journal was built in the days before electronic subscription via library consortia became the leading economical background. Makoto was always an active board member, reviewer, and supporter of the journal. We as editors, the editorial office and the publishers at Springer will always be grateful for that.

However, all his positions and achievements cannot really describe a human being, who has gone from us, sufficiently. We must talk about his character, his personality, and if at all possible about his soul. This is easier with Makoto than most other persons because Makoto had a very open heart. So open, that one felt this immediate warmth and comfort as soon as one met him for the first time. He loved people and he was very trustful with everybody. I experienced his great empathy several times when I visited him on professional and private occasions, one time together with my daughter Anika in Tokyo and on another occasion when he came with Morio Tonogi to visit me in Munich and Salzburg.

In addition to his professionalism in dentistry and the love for his family and everybody he met, his big love belonged to music and singing. Makoto was a member of the Japan National Chorus. His repertoire reached from classic to jazz and pop. Every time I met Makoto outside a professional meeting, I asked him to give me a probe of his singing. I will never forget him singing "Hey Jude" on several occasions in Japanese karaoke places and "Edelweiss" from Sound of Music together with Morio Tonogi in the Salzburg MOMA café during a brunch. Maybe the pictures accompanying this obituary can give a tiny impression to those who did not know him personally.

Makoto Kikuchi DDS Ph.D. will never be forgotten, he and his refreshing smile will continue to live in our hearts and memories. 


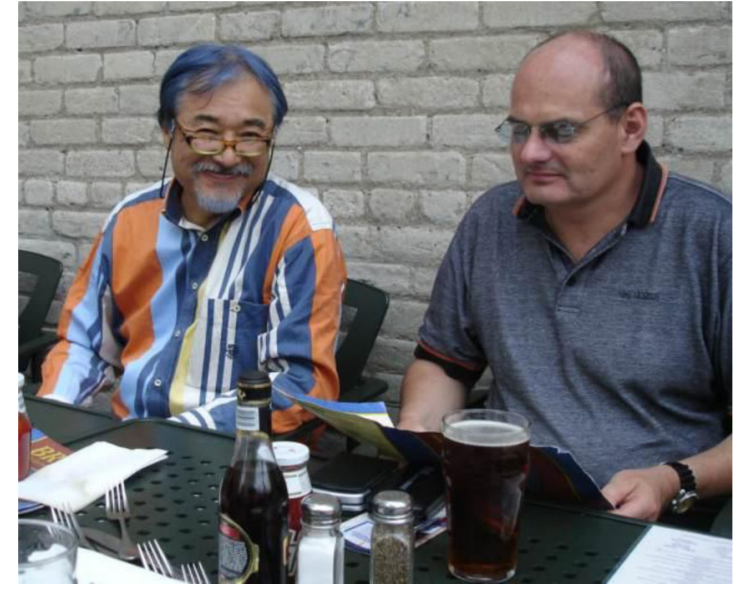

Makoto and the author during a break at an APSS meeting in Minneapolis.

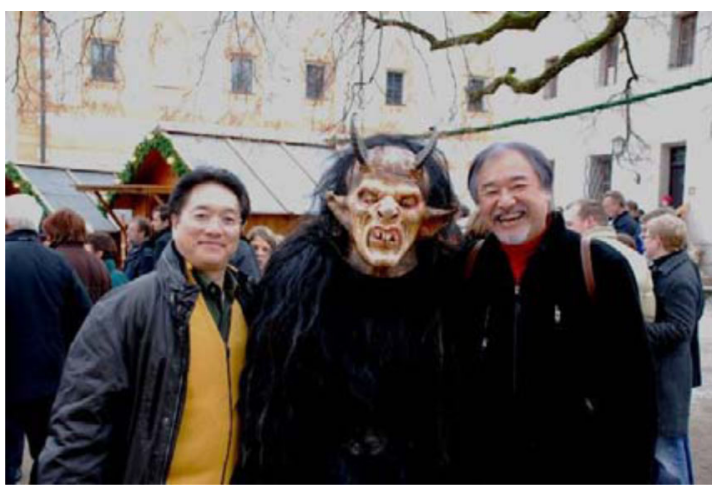

Makoto and Moro Tonogi with a scary "Perchten" guy at St. Niklas day in the courtyard of Salzburg Castle.

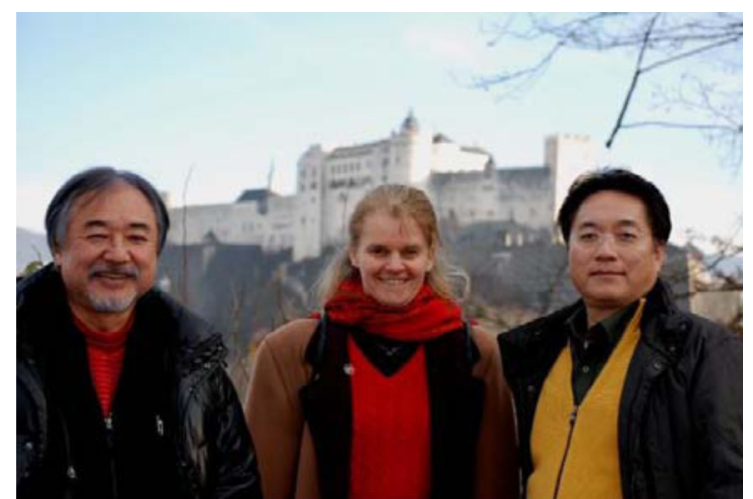

Makoto and Morio with Dr. Sigrid Hader MD from 3M Espe in front of Salzburg Castle.

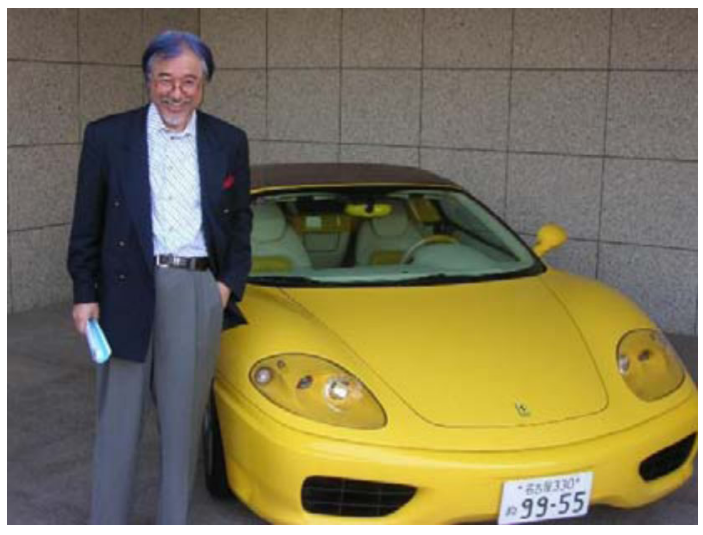

Makoto in front of a Ferrari in Tokyo, which would have fit him perfectly.

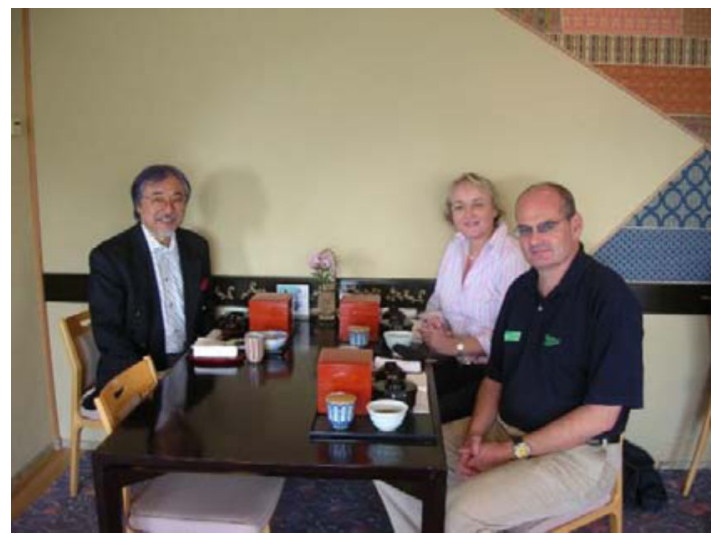

Makoto, the author, and Susanne Schwarting DDS, chairwoman of the German Dental Sleep Medicine Society, during a professional visit in Tokyo. 